\title{
High-intensity focussed ultrasound (HIFU) als salvagebehandeling van recidiverend prostaatcarcinoom: stand van zaken wetenschap en praktijk. Een review van systematische reviews
}

\author{
Valery E. P. P. Lemmens · Olav G. J. M. van Aubel
}

Published online: 19 May 2020

(C) The Author(s) 2020

\begin{abstract}
Samenvatting Er verschijnen steeds meer oorspronkelijke studies naar de veiligheid en effectiviteit van HIFU als salvagebehandeling van een lokaal recidief van het prostaatcarcinoom (Pca). Ook verschenen recentelijk meerdere systematische reviews (SR's) over dit onderwerp. Deze review van SR's geeft inzicht in de huidige stand van wetenschap en praktijk ten aanzien van salvage-HIFU van een lokaal recidiverend Pca. De meest recente en tevens grootste SR toont bij een lokaal recidief na bestraling geen verschil in overleving tussen HIFU en salvage radicale prostatectomie of salvagebestraling. De morbiditeit na salvage-HIFU was lager dan na een salvage radicale prostatectomie. In verband met de hoge morbiditeit bij een salvage radicale prostatectomie wordt deze zelden uitgevoerd. HIFU als salvagebehandeling kan daarom worden gezien als een veelbelovend alternatief. Dit geldt zeker voor patiëntengroepen bij wie leeftijd, ziektestadium en wens van de patiënt in de richting wijzen van afzien van agressievere therapieën, en bij wie het risico op bijwerkingen en vermindering van de kwaliteit van leven te hoog wordt geacht. De huidige evidence geeft voldoende aanleiding om, in afwachting van studies met hogere bewijskracht, HIFU als salvagebehandeling aan te bieden in plaats van androgeendeprivatietherapie, dan wel niet te behandelen.
\end{abstract}

Trefwoorden recidief na radiotherapie $\cdot$ HIFU . systematische review

prof. dr. V. E. P. P. Lemmens

Erasmus MC, Rotterdam, Nederland

dr. O. G. J. M. van Aubel (ه)

Hifu Kliniek Nederland, Etten-Leur, Nederland

o.vanaubel@gmail.com
High-intensity focused ultrasound (HIFU) as salvage treatment in radio-recurrent prostate cancer: current scientific background and practice. A review of systematic reviews

Abstract An increasingly number of original studies on safety and efficacy of HIFU as salvage treatment in local radio-recurrent prostate cancer has been published. This review of systematic reviews (SRs) gives insight in the current practice and scientific background of salvage HIFU in radio-recurrent prostate cancer. The most recent and also largest SR review included showed no difference in survival between HIFU and salvage radical prostatectomy. However, the morbidity after salvage HIFU was lower than after salvage radical prostatectomy. Pending future studies with higher evidence salvage HIFU might be seen as promising alternative treatment in patients with local radiorecurrent prostate cancer. Certainly for the patient in whom age and patient's wishes and disease stage point to refraining from more aggressive therapy. The currently available evidence provides sufficient grounds to offer HIFU as salvage treatment rather than no treatment or androgen deprivation therapy.

Keywords radiorecurrent · HIFU · systematic review

\section{Inleiding}

Kanker van de prostaat is de meest voorkomende vorm van kanker bij mannen in Nederland: in 2018 zijn meer dan 12.000 mannen nieuw gediagnosticeerd met een prostaatcarcinoom (Pca), een toename van ruim $250 \%$ ten opzichte van 1990 [1]. Ongeveer de helft van hen had lokale ziekte van wie weer de helft in aanmerking kwam voor active surveillance. De andere helft onderging in 2018 na MDO-overleg en advies radiotherapie of een radicale prostatectomie. 


\title{
Hier staat een advertentie.
}

\author{
cef bohn \\ stafleu \\ van loghum
}

Houten 2020 


\title{
Hier staat een advertentie.
}

\author{
cef bohn \\ stafleu \\ van loghum
}

Houten 2020 
In 2018 werden ongeveer 1.000 patiënten met radiotherapie behandeld. De kans op een lokaal recidief of metastasering binnen vijf jaar na radiotherapie is afhankelijk van de gradatie $30-60 \%$. Nieuwe diagnostische mogelijkheden (multiparametrische MRI van de prostaat, PSMA PET-scan en gerichte biopten) verbeteren het onderscheid tussen wie in aanmerking komt voor een salvagebehandeling en wie niet.

Bij een lokaal recidief zijn er - afhankelijk van eerdere behandelingen, plaats en grootte van het recidief, kenmerken van de primaire tumor en het risicoprofiel, de levensverwachting, de conditie en wens van de patiënt - verschillende behandelopties beschreven: salvage radicale prostatectomie, salvageradiotherapie, salvagebrachytherapie, salvagecryotherapie en salvage HIFU-therapie. Laatstgenoemde behandeling wordt in Nederland momenteel op relatief beperkte schaal buiten studieverband toegepast. Focale behandeling met HIFU en radiotherapie is mogelijk geworden door verbeterde diagnostiek en fusietechnieken [2], met minder kans op complicaties in vergelijking met het behandelen van de gehele prostaat [3-5]. Het behandelen van alleen de tumor of de indexlaesie in plaats van de gehele prostaat is controversieel [6]. Er zijn ook geen prospectieve randomised controlled trials (RCT's) uitgevoerd die behandeling van de gehele prostaat vergelijken met behandeling van de tumor alleen. De focale salvagebehandeling (HIFU en radiotherapie) vallen buiten de scope van deze review.

In Nederland krijgen patiënten met lokaal recidief na radiotherapie géén salvagebehandeling aangeboden, maar androgeendeprivatietherapie (ADT), met alle nadelen van dien. Indien patiënten geen ADT willen, wordt er afgewacht. De salvage HIFU-behandeling voor lokaal recidiverend Pca is in Nederland niet opgenomen in de behandelrichtlijn, op grond van het feit dat valide RCT's ontbreken. Dat is ook de reden dat een behandeling met HIFU niet wordt vergoed door de meeste Nederlandse zorgverzekeraars. Ook naar wél in de richtlijnen opgenomen salvagebehandelingen zijn geen RCT's uitgevoerd, maar die behandelingen worden wel vergoed, omdat ze in de richtlijn zijn opgenomen.

Recentelijk zijn er echter een groot aantal studies en een aantal systematische reviews (SR's) gepubliceerd over de effectiviteit van HIFU als salvagebehandeling voor een lokaal recidief van het Pca na radiotherapie. In deze review van SR's wordt op basis van deze recente literatuur een update gegeven van de stand van wetenschap en praktijk aangaande de effectiviteit van HIFU als salvagebehandeling voor een lokaal recidief van het Pca.

\section{Methoden}

De laatste jaren is er een aantal (systematische) reviews gepubliceerd aangaande de effectiviteit van HIFU als salvagebehandeling voor lokaal recidiefPca. Om die reden is er in dit rapport gekozen voor een 'review van reviews' aanpak. Bij deze aanpak wordt de informatie die is verzameld en geanalyseerd in reviews en eventuele meta-analyses systematisch hergebruikt, en wordt de beschikbare evidence uit de verschillende reviews afgewogen tegen de (methodologische) kwaliteit van de reviews, en de in- en exclusiecriteria van de reviews. Deze bevinding wordt vervolgens aangevuld met de bevindingen van beschikbare gerandomiseerde studies met een dermate recente publicatiedatum dat zij niet in een van de (systematische) reviews zijn opgenomen, uitgaande van de in- en exclusiecriteria die het meest gebruikelijk bleken in de geïncludeerde reviews. De conclusies die werden getrokken in de afzonderlijke reviews worden daartegen afgezet, waarna - op basis van een synthese van alle resultaten - een samenvattende conclusie wordt geformuleerd over de effectiviteit van HIFU als salvagebehandeling, volgens de huidige stand van de wetenschap.

Omdat een oorspronkelijke studie, herhaaldelijk geïncludeerd (kan) worden in reviews met overlappende in- en exclusiecriteria, is ervoor gekozen om alleen reviews met publicatiedatum na 1 januari 2014 te includeren. De volgende zoekstrategie werd uitgevoerd in PubMed: ("high-intensity focused ultrasound ablation" [MeSH Terms] OR ("high-intensity" [All Fields] AND "focused" [All Fields] AND "ultrasound" [All Fields] AND "ablation" [All Fields]) OR "highintensity focused ultrasound ablation" [All Fields] OR "hifu" [All Fields]) OR "high intensity focussed ultrasound" [All Fields] AND "prostate cancer" [All Fields] AND "salvage" [All Fields] Publication date: 201-01-2014. Aanvullende inclusiecriteria waren: systematische of narratieve reviews en/of meta-analyses waarbij orginele studies aangaande de klinische effectiviteit van HIFU bij mensen als salvagebehandeling geïncludeerd werden: case serie, retrospectief en prospectief cohort, single- en multicenterstudie, vergelijkende studie, fase 2-, 3- of 4-studie, (niet-)gerandomiseerd clinical trial, in de Engelse of Nederlandse taal.

Op basis van de titel werd een eerste selectie gemaakt naar type studie (review, meta-analyse, anders). Van alle geselecteerde artikelen werd het abstract gelezen, op basis waarvan een verdere selectie werd gemaakt, al dan niet na lezing van de volledige tekst van het artikel.

\section{Resultaten}

De zoekstrategie leverde 62 studies op. Daarvan werden er 18 in PubMed aangeduid als review, 2 als clinical trial en 1 als meta-analyse. Na eerste selectie op titel bleven er 28 artikelen over; daarvan werd het abstract gelezen. Na beoordeling van de abstracts en toepassing van de inclusiecriteria werd van 14 artikelen de volledige tekst gelezen en uiteindelijk werden 7 reviews geïncludeerd [7-13]. De SR's van Valerio et al. [14], Fahkrejahani et al. [15] en Duijzentkunst 
Tabel 1 Eigenschappen van de in dit rapport geïncludeerde reviews

\begin{tabular}{|c|c|c|c|c|c|c|}
\hline auteur en jaartal & type review & populatie & interventie & uitkomstmaten & $\begin{array}{l}\text { methodol. } \\
\text { kwaliteita }^{\text {a }}\end{array}$ & $\begin{array}{l}\text { publicatie- } \\
\text { datum }^{b}\end{array}$ \\
\hline $\begin{array}{l}\text { Hennequin et al. } \\
\text { (2017) [7] }\end{array}$ & narratief & $\begin{array}{l}\text { recidiverend Pca } \\
\text { na bestraling }\end{array}$ & $\begin{array}{l}\text { HIFU, cryotherapie, prosta- } \\
\text { tectomie, stereotactische } \\
\text { radiotherapie, brachytherapie }\end{array}$ & $\begin{array}{l}\text { biochemische relapse, overall } \\
\text { survival, Pca-specifieke overle- } \\
\text { ving, progressievrije overleving, } \\
\text { bijwerkingen }\end{array}$ & nee & 2017 \\
\hline $\begin{array}{l}\text { Golbari et al. } \\
\text { (2017) [8] }\end{array}$ & narratief & $\begin{array}{l}\text { recidiverend Pca } \\
\text { na bestraling }\end{array}$ & $\begin{array}{l}\text { HIFU, cryotherapie, prosta- } \\
\text { tectomie, stereotactische } \\
\text { radiotherapie, brachytherapie }\end{array}$ & overall survival, bijwerkingen & nee & 2017 \\
\hline $\begin{array}{l}\text { Golan et al. } \\
\text { (2017) [9] }\end{array}$ & $\begin{array}{l}\text { narratief/ } \\
\text { systematisch }\end{array}$ & gelokaliseerde Pca & HIFU als hemiablatie & $\begin{array}{l}\text { bioptbewezen recidief, metastase- } \\
\text { vrije overleving, continentie, bijwer- } \\
\text { kingen, kwaliteit van leven }\end{array}$ & nee & 2014 \\
\hline $\begin{array}{l}\text { Chaussy et al. } \\
(2017)[10]\end{array}$ & narratief & gelokaliseerde Pca & $\begin{array}{l}\text { HIFU als salvagebehandeling } \\
\text { na radicale prostatectomie of } \\
\text { radiotherapie, brachytherapie }\end{array}$ & $\begin{array}{l}\text { biochemische failure rates, } \\
\text { bijwerkingen }\end{array}$ & nee & 2011 \\
\hline $\begin{array}{l}\text { Mendenhall et al. } \\
(2014)[11]\end{array}$ & narratief & $\begin{array}{l}\text { lokaal recidief na } \\
\text { radiotherapie }\end{array}$ & $\begin{array}{l}\text { HIFU als salvagebehandeling } \\
\text { na radiotherapie }\end{array}$ & $\begin{array}{l}\text { biochemische failure rates, } \\
\text { bijwerkingen }\end{array}$ & nee & 2011 \\
\hline $\begin{array}{l}\text { Ramsay et al. } \\
(2015)[12]\end{array}$ & systematisch & $\begin{array}{l}\text { lokaal recidief na } \\
\text { radiotherapie }\end{array}$ & $\begin{array}{l}\text { HIFU als salvagebehandeling } \\
\text { na radiotherapie }\end{array}$ & incontinentie, bijwerkingen & ja & 2006 \\
\hline $\begin{array}{l}\text { Zdrojowy et al. } \\
(2016) \text { [13] }\end{array}$ & systematisch & $\begin{array}{l}\text { lokaal recidief na } \\
\text { radiotherapie }\end{array}$ & $\begin{array}{l}\text { HIFU als salvagebehandeling } \\
\text { na radiotherapie }\end{array}$ & $\begin{array}{l}\text { ziektespecifieke, ziektevrije en } \\
\text { metastasevrije overleving, bijwer- } \\
\text { kingen }\end{array}$ & nee & 2014 \\
\hline
\end{tabular}

et al. [16] werden niet geïncludeerd, omdat deze volledig overeenkwamen met de oorspronkelijke studies naar salvage HIFU die reeds waren geïncludeerd. De SR van Palermo et al. [17] kon niet geïncludeerd omdat de volledige tekst van het artikel niet beschikbaar was.

De reviews includeerden oorspronkelijke studies tot en met medio 2017. Twee reviews waren systematisch van opzet; één review gebruikte een systematische zoekopdracht, maar van deze review was de rapportage narratief. De overige reviews waren geheel narratief van aard. De meeste reviews includeerde mannen met een recidief na bestraling van een gelokaliseerd Pca. Slechts één studie vergeleek HIFU direct cijfermatig met de uitkomsten na radiotherapie en/of radicale prostatectomie. Niet alle reviews beperkten zich tot HIFU in de salvagetherapiesetting. De uitkomstmaten betroffen veelal een combinatie van oncologische en functionele uitkomstmaten. Zie tab. 1.

Geen van de reviews includeerde kwaliteit van leven, en geen enkele review evalueerde de kosteneffectiviteit. Slechts één review maakte gebruik van strikte kwaliteitstoetsing van de geïncludeerde oorspronkelijke studies. De review van Golbari [8] omvatte de meest recente resultaten met inclusie van oorspronkelijke studies gepubliceerd tot medio 2017.

Er was variatie in de kwaliteit van de geïncludeerde reviews in dit rapport. Definities van inclusiecriteria, patiëntenpopulatie, gevolgde methodologie, uitkomstmaten, voorgaande of vervolgtherapieën, etc. werden wisselend beschreven. De reviews van Golan et al. [9] en Ramsay et al. [12] onderscheidden zich van de andere geïncludeerde reviews op het ge- bied van methodologische kwaliteit, met name door hun systematische aanpak.

Omdat in de reviews veelal dezelfde oorspronkelijke studies zijn gebruikt, zit er uiteraard overlap tussen de reviews. Het aantal in de reviews opgenomen studies varieerde van twee tot acht, het aantal deelnemers per studie van 87 tot 803 en de mediane followupduur varieerde van zeven maanden tot zeven jaar. In een enkele narratieve review wordt geen van beide kenmerken vermeld. Zie tab. 2.

Geen van de reviews bevatte een RCT. De meeste studies waren prospectieve single-center casestudies; een enkele studie was retrospectief van aard en een enkele includeerde deelnemers uit meerdere centra. Rechtstreeks vergelijkende data bleken slechts beperkt beschikbaar.

De ziektespecifieke overleving na salvage-HIFU bedroeg $80 \%$ na maximaal zeven jaar en de ziektevrije overleving 25-75\% (afhankelijk van follow-upduur). De metastasevrije overleving na zeven jaar bedroeg $80 \%$. De cijfermatig vergelijkende review van Golbari et al. vond geen verschil in overleving tussen salvageHIFU vs. salvage radicale prostatectomie of bestraling [8]. De continentie na salvage-HIFU liep uiteen van $50-93 \%$. Slechts één review rapporteerde potentieproblemen.

Stenose na salvage-HIFU werd gerapporteerd bij $14-36 \%$ en een urethrorectale fistel bij 3-16\% van de behandelde mannen.

\section{Discussie}

Er is de afgelopen jaren een toenemend aantal oorspronkelijke studies gepubliceerd aangaande de veiligheid en effectiviteit van HIFU als salvagebehande- 
Tabel 2 Uitkomsten van de in dit rapport geïncludeerde reviews

\begin{tabular}{|c|c|c|c|c|c|c|c|}
\hline $\begin{array}{l}\text { auteur en } \\
\text { jaartal }\end{array}$ & N studies & $\begin{array}{l}\text { type geïnclu- } \\
\text { deerde studies }\end{array}$ & $\begin{array}{l}\mathrm{N} \text { patiën- } \\
\text { ten }\end{array}$ & $\begin{array}{l}\text { niveau } \\
\text { van evi- } \\
\text { dence }\end{array}$ & $\begin{array}{l}\text { mediane FU } \\
\text { (gem., range) }\end{array}$ & belangrijkste uitkomsten na HIFU & conclusie \\
\hline $\begin{array}{l}\text { Hennequin } \\
\text { et al. } \\
\text { (2017) [7] }\end{array}$ & $\begin{array}{l}2 \text { naar } \\
\text { salvage- } \\
\text { HIFU }\end{array}$ & $\begin{array}{l}2 \text { single-center } \\
\text { caseseries }\end{array}$ & 355 & laag & $\begin{array}{l}\text { grootste stu- } \\
\text { die: } 48 \text { mnd. } \\
\text { (max. } 7 \text { jaar) }\end{array}$ & $\begin{aligned} \text { - } & \text { 7-jaars Pca-specifieke overleving } \\
& 80 \% \\
- & 7 \text {-jaars metastasevrije overleving } \\
& 80 \% \\
- & 5 \text {-jaars progressievrije overleving } \\
& 21-45 \%\end{aligned}$ & $\begin{array}{l}\text { - HIFU is een behandelingsoptie bij } \\
\text { relapse na bestraling. } \\
\text { - Algemeen: prospectieve, klinisch } \\
\text { vergelijkende studies worden } \\
\text { aanbevolen. }\end{array}$ \\
\hline $\begin{array}{l}\text { Golbari } \\
\text { et al. } \\
(2017)[8]\end{array}$ & 12 & $\begin{array}{l}\text { single/multi- } \\
\text { center } \\
\text { caseseries, } \\
\text { prospectief, } \\
\text { vergelijkende } \\
\text { studie }\end{array}$ & 803 & laag & $\begin{array}{l}\text { gem. } \\
\text { 9-64 mnd. }\end{array}$ & $\begin{array}{l}\text { - geen verschil in overleving HIFU } \\
\text { vs. prostatectomie of bestraling } \\
\text { - lagere morbiditeit na HIFU vs. } \\
\text { prostatectomie }\end{array}$ & $\begin{array}{l}\text { - Bemoedigende resultaten na } \\
\text { HIFU, duidelijke rol voor HIFU als } \\
\text { salvagebehandeling. }\end{array}$ \\
\hline $\begin{array}{l}\text { Golan } \\
\text { et al. } \\
\text { (2017) [9] }\end{array}$ & $\begin{array}{l}2 \text { naar } \\
\text { salvage- } \\
\text { HIFU }\end{array}$ & $\begin{array}{l}\text { prospectieve, } \\
\text { single/2-center } \\
\text { caseseries }\end{array}$ & 87 & laag & $\begin{array}{l}16,3-17 \text { mnd. } \\
(10-29)\end{array}$ & $\begin{array}{l}\text { - } \text { metastasevrije overleving } \\
88-95 \% \\
\text { - } \text { biochemisch-recidiefvrije overle- } \\
\text { ving } 42-67 \% \\
\text { - incontinentie } 25 \% \text { (onvrijwillig } \\
\text { urineverlies of gebruik van pads) } \\
\text { - kwaliteit van leven: verbetering } \\
\text { op prostaatsymptoomscore/ } \\
\text { verslechtering erectiele disfunctie }\end{array}$ & $\begin{array}{l}\text { - HIFU is veilig alternatief voor } \\
\text { standaardbehandeling, met } \\
\text { weinig bijwerkingen. } \\
\text { - Oncologische resultaten lijken } \\
\text { gunstig, maar langere follow-up } \\
\text { en prospectieve trials zijn noodza- } \\
\text { kelijk voor de integratie van HIFU } \\
\text { in behandelrichtlijnen. }\end{array}$ \\
\hline $\begin{array}{l}\text { Chaussy } \\
\text { et al. } \\
\text { (2017) [10] }\end{array}$ & $\begin{array}{l}4 \text { naar } \\
\text { salvage- } \\
\text { HIFU }\end{array}$ & $\begin{array}{l}\text { single-center } \\
\text { caseseries }\end{array}$ & n.b. & laag & max. 5 jaar & $\begin{array}{l}\text { - na salvage-HIFU geen hogere } \\
\text { complicatierates dan na primaire } \\
\text { HIFU } \\
\text { - na salvage-HIFU bij patiënten met } \\
\text { failure na radicale prostatectomie, } \\
91 \% 5 \text {-jaars biochemisch-recidief- } \\
\text { vrije overleving }\end{array}$ & $\begin{array}{l}\text { - HIFU is een behandelingsoptie } \\
\text { voor lokale recidieven, waar } \\
\text { conventionele therapieën vaak } \\
\text { niet meer toegepast kunnen } \\
\text { worden. }\end{array}$ \\
\hline $\begin{array}{l}\text { Mendenhall } \\
\text { et al. } \\
\text { (2014) [11] }\end{array}$ & $\begin{array}{l}4 \text { naar } \\
\text { salvage- } \\
\text { HIFU }\end{array}$ & $\begin{array}{l}\text { single-center } \\
\text { caseseries }\end{array}$ & 220 & laag & $\begin{array}{l}7,4-36 \text { mnd. } \\
(3-121)\end{array}$ & $\begin{array}{l}\text { - } 3 \text {-jaars biochemisch-progressie- } \\
\text { vrije overleving } 25-53 \% \text { (afhanke- } \\
\text { lijk van risicostratificatie) } \\
\text { - } 5 \text {-jaar biochemisch-progressie- } \\
\text { vrije overleving } 52 \% \\
\text { - incontinentie } 50 \%, 32 \% \\
\text { graad } 2-3 \\
\text { - stenose } 14-36 \% \text {, urethrorectale } \\
\text { fistel 3-7\% }\end{array}$ & $\begin{array}{l}\text { - Er is geen specifieke conclusie } \\
\text { geformuleerd met betrekking tot } \\
\text { salvage HIFU. }\end{array}$ \\
\hline $\begin{array}{l}\text { Ramsay } \\
\text { et al. } \\
\text { (2015) [12] }\end{array}$ & $\begin{array}{l}1 \text { naar } \\
\text { salvage- } \\
\text { HIFU }\end{array}$ & $\begin{array}{l}\text { retrospectieve } \\
\text { single-center- } \\
\text { studie }\end{array}$ & n.b. & laag & 15 mnd. & $\begin{array}{l}\text { - incontinentie } 7 \% \\
\text { - stenose } 17 \% \text {, urethrorectale fistel } \\
\quad 6 \%\end{array}$ & $\begin{array}{l}\text { - Er zijn weinig data voorhanden. } \\
\text { Er zijn prospectieve studies van } \\
\text { goede kwaliteit noodzakelijk, ook } \\
\text { ter evaluatie van langetermijnef- } \\
\text { fecten. }\end{array}$ \\
\hline $\begin{array}{l}\text { Zdrojowy } \\
\text { et al. } \\
(2016)[13]\end{array}$ & 8 & $\begin{array}{l}\text { voornamelijk } \\
\text { prospectieve, } \\
\text { single-center } \\
\text { caseseries }\end{array}$ & n. b. & laag & $\max .7$ jaar & $\begin{array}{l}\text { - ziektespecifieke en metastasevrije } \\
\text { overleving } 80 \% \\
\text { - ziektevrije overleving } 25-75 \% \\
\text { - incontinentie } 10-50 \% \\
\text { - stenose } 17 \% \text {, urethrorectale fistel } \\
\text { 3-16\% } \\
\text { - over het algemeen meer complica- } \\
\text { ties na salvage-HIFU dan na HIFU } \\
\text { in primaire setting }\end{array}$ & $\begin{array}{l}\text { - Lokale salvagebehandelingen } \\
\text { zoals HIFU zijn een behandelings- } \\
\text { optie bij een lokale recidief na } \\
\text { bestraling. } \\
\text { - Vanwege een gebrek aan ge- } \\
\text { randomiseerde data is het niet } \\
\text { mogelijk om heldere aanbevelin- } \\
\text { gen te doen. }\end{array}$ \\
\hline
\end{tabular}

ling van een recidief van het gelokaliseerd Pca. Daarnaast is er recent ook een aantal reviews verschenen over dit onderwerp. Deze reviews werden in dit rapport gebruikt om tot een overzicht te komen van de huidige stand van wetenschap en praktijk met betrekking tot salvagebehandeling van het recidiverend Pca met HIFU.

De zeven in dit rapport geïncludeerde reviews verschilden sterk van elkaar met betrekking tot gebruikte methodologie en kwaliteit; twee reviews waren systematisch van opzet. De in de reviews opgenomen oor- spronkelijke studies betroffen in de meeste gevallen prospectieve single-centerstudies. De definities van de gebruikte inclusiecriteria, de geïncludeerde patiëntenpopulaties en de definities van de uitkomstmaten verschilden sterk tussen de individuele studies en de geïncludeerde reviews. Dat bemoeilijkt de interpretatie en vergelijkbaarheid van de resultaten. Er zijn tot op heden geen gerandomiseerde en/of vergelijkende klinische studies naar het effect van HIFU gepubliceerd. 
De oncologische uitkomsten zijn veelal gemeten binnen één tot vijf jaar; de minderheid van de studies had een follow-up van langer dan 10 jaar. De oncologische en met name de functionele uitkomsten zijn echter bemoedigend voor het gebruik van HIFU in de salvagesetting, zoals ook wordt geconcludeerd in de meest recente en qua aantal geïncludeerde patiënten, grootste review. Daarbij werd in de setting van een recidief na bestraling geen verschil in overleving gevonden tussen HIFU vs. salvage radicale prostatectomie of bestraling, en de morbiditeit na salvage-HIFU was lager dan na salvage radicale prostatectomie.

\section{Conclusie}

Vanwege het gunstige bijwerkingenprofiel en de nietinferieure oncologische uitkomsten ten opzichte van radicale prostatectomie of bestraling kan een salvageHIFU worden gezien als een veelbelovend alternatief voor salvagebehandeling van het lokaal recidiverend Pca. Dit geldt zeker voor specifieke patiëntengroepen bij wie leeftijd, ziektestadium en wens van de patiënt in de richting wijzen van afzien van agressievere therapie, ofwel patiënten bij wie het risico op bijwerkingen en daardoor vermindering van de kwaliteit van leven te hoog wordt geacht. Gerandomiseerde vergelijkende klinische studies of prospectieve series met lange follow-up en duidelijk afgebakende inclusiecriteria en heldere uitkomstdefinities zijn nodig om een hoger level of evidence te verkrijgen. Prospectieve gerandomiseerde studies voor het onderbouwen en introduceren van nieuwe operatietechnieken zijn altijd gewenst, maar in de praktijk vaak niet haalbaar, omdat er grote verschillen zijn in de belasting die de verschillende operaties voor de patiënt met zich meebrengen. Een voorbeeld hiervan is de in 2015 mislukte gerandomiseerde Duitse PREFERE - Das Scheitern einer (fast) perfekten Studie [18]. De huidige beschikbare evidence uit SR's geeft echter voldoende aanleiding om, in afwachting van toekomstige studies met hogere bewijskracht, HIFU als salvagebehandeling aan te bieden in plaats van ADT dan wel niet behandelen, en in aanmerking te laten komen voor vergoede zorg.

Open Access This article is distributed under the terms of the Creative Commons Attribution 4.0 International License (http://creativecommons.org/licenses/by/4.0/), which permits unrestricted use, distribution, and reproduction in any medium, provided you give appropriate credit to the original author(s) and the source, provide a link to the Creative Commons license, and indicate if changes were made.

\section{Literatuur}

1. NKR-cijfers/ IKNL.IKNL 2019. Beschikbaar via www. cijfersoverkanker.nl. Geraadpleegd op 10 februari 2020.

2. Ingrosso G,BecheriniC, LanciaA, CainiS, OstP,FrancoliniG, et al. Nonsurgical salvage local therapies for radiorecurrent prostate cancer: asystematic review and meta-analysis. Eur Urol. 2019; https://doi.org/10.1016/j.euo.2018.12.011.
3. Aoun F, Albisinni S, Biaou I, Peltier A, Limani K, Roumeguère $\mathrm{T}$, et al. Salvage hemiablation high intensity focused ultrasound for unilateral radio-recurrent prostate cancer. Prog Urol. 2019;29(12):627-33.

4. Hostiou T, Gelet A, Chapelon JY, Rouvière O, Mège-Lechevalier F, Lafon C, et al. Salvage high-intensity focused ultrasound for locally recurrent prostate cancer after lowdose-rate brachytherapy: oncological and functional outcomes. BJU Int. 2019;124(5):746-57.

5. Son M van, Peters M, Moerland M, Kerkmeijer L, Lagendijk J, Voort van Zyp J van der. Focal salvage treatment of radiorecurrent prostate cancer: a narrative review of current strategies and future perspectives. Cancers (Basel). 2018;3(10):12-E480.

6. Crouzet S, Blana A, Murat FJ, Pasticier G, Brown SCW, Conti GN, et al. Salvage high-intensity focused ultrasound (HIFU) for locally recurrent prostate cancer after failed radiation therapy: multi-institutional analysis of 418 patients. BJU Int. 2017;119(6):896-904.

7. Hennequin C, Hannoun-Lévi JM, Rozet F. Management of local relapse after prostate cancer radiotherapy: surgery or radiotherapy? Cancer Radiother. 2017;21(6-7):433-6.

8. Golbari NM, Katz AE. Salvage therapy options for local prostate cancer recurrence after primary radiotherapy: aliterature review. Curr Urol Rep. 2017;18(8):63.

9. Golan R, Bernstein AN, McClure TD, Sedrakyan A, Patel NA, Parekh DJ, et al. Partial gland treatment of prostate cancer using high-intensity focused ultrasound in the primary and salvage settings: a systematic review. J Urol. 2017;198(5):1000-9.

10. Chaussy CG, Endourol TSJ. High-intensity focused ultrasound for the treatment of prostate cancer: a review. JEndourol. 2017;31(S1):S30-S7.

11. Mendenhall WM, Henderson RH, Hoppe BS, Nichols RC, Mendenhall NP. Salvage of locally recurrent prostate cancer after definitive radiotherapy. Am J Clin Oncol. 2014;37(4):411-6.

12. Ramsay CR, Adewuyi TE, Gray J, Hislop J, Shirley MD, Jayakody S, et al. Ablative therapy for people with localised prostate cancer: a systematic review and economic evaluation. Health Technol Assess. 2015;19(49):1-490.

13. Zdrojowy R, Dembowski J, Małkiewicz B, Tupikowski K, Krajewski W. Salvage local therapy for radiation-recurrent prostate cancer-where are we? Cent European J Urol. 2016;69(3):264-70.

14. Valerio M, Cerantola Y, Eggener SE, Lepor H, Polascik TJ, Villers A, et al. New and established technology in focal ablation of the prostate: a systematic review. Eur Urol. 2017;71(1):17-34.

15. FakhrejahaniF, MadanRA, DahutWL. Managementoptions for biochemically recurrent prostate cancer. Curr Treat Options Oncol. 2017;18(5):26.

16. Duijzentkunst DA, Peters M, Voort van Zyp JR van der, Moerland MA, Vulpen Mvan. Focal salvage therapy for local prostate cancer recurrences after primary radiotherapy: acomprehensivereview. WorldJ Urol. 2016;34(11):1521-31.

17. Palermo G, Foschi N, D’Agostino D, Sacco E, Bassi P, Pinto F. Local relapse of prostate cancer after primary definitive treatment: the management. Minerva Urol Nefrol. 2016;68(3):282-92.

18. Klotz T, Bschleipfer T. PREFERE-Das Scheitern einer (fast) perfekten Studie. Urologe. 2017;56:231-2.

prof. dr. Valery E.P.P. Lemmens, hoogleraar Kankerepidemiologie

dr. Olav G.J.M. van Aubel, uroloog 


\title{
Hier staat een advertentie.
}

\author{
cef bohn \\ stafleu \\ van loghum
}

Houten 2020 


\title{
Hier staat een advertentie.
}

\author{
cef bohn \\ stafleu \\ van loghum
}

Houten 2020 